\title{
Comparison of CARTO LAT Maps and Non-Invasive Activation Maps for Patients with Intraventricular Conduction Disturbance During Sinus Rhythm
}

\author{
Margarita Budanova ${ }^{1}$, Mikhail Chmelevsky ${ }^{1,2}$, Stepan Zubarev ${ }^{1}$, Danila Potyagaylo ${ }^{2}$, Boris Rudic ${ }^{3}$, \\ Erol Tueluemen ${ }^{3}$, Martin Borggrefe ${ }^{3}$ \\ ${ }^{1}$ Almazov National Medical Research Center, Saint-Petersburg, Russia \\ ${ }^{2}$ EP Solutions SA, Yverdon-les-Bains, Switzerland \\ ${ }^{3}$ Department of Medicine, University Medical Center Mannheim, Mannheim, Germany
}

\begin{abstract}
Non-invasive electrocardiographic imaging (ECGI) shows high accuracy for topical diagnosis of focal arrhythmias. Activation maps obtained by ECGI allow for the analysis of excitation propagation during sinus rhythm with conduction disturbances. Nevertheless, noninvasive activation patterns have not been compared with the results of invasive mapping. In this article, we present the results of a qualitative comparison of non-invasive activation maps and CARTO LAT maps.
\end{abstract}

\section{Introduction}

The results of recent validation studies showed high precision of non-invasive electrocardiographic imaging (ECGI) for focal arrhythmia localization [1-5]. Successful ablation of arrhythmias and colocalization of the early activation zone (EAZ) with the pacing lead tip can be reliable methods of accuracy verification. The ability to adequately visualize excitation propagation for single ectopic foci has also been demonstrated using ECGI.

It seems to be more difficult to display the individual processes of myocardial activation in cases of intraventricular conduction disturbances. Some studies have described pathological excitation sequences in patients with left bundle branch block (LBBB) [6, 7]. However, we do not have reliable methods of verifying interventricular conduction disturbances. Therefore, we can only be guided by theoretic data and data from experiments simulating abnormal activation patterns in bundle branch block modelling [7].

It is believed that invasive mapping can more accurately display myocardial activation processes due to receiving information from the tip of the mapping catheter directly from the heart surface. Presumably, activation maps obtained by non-invasive ECGI allow the analysis of the excitation pattern during sinus rhythm with conduction disturbances. In this study, we made a qualitative comparison between invasive and non- invasive activation maps for patients with conduction disturbances.

\section{Aim}

Comparison of CARTO LAT maps and non-invasive activation maps for patients with intraventricular conduction disturbance and assessment of the excitation propagation.

\section{Methods}

The study was performed in University Medical Centre Mannheim (Mannheim, Germany) and was approved by the local ethics committee. Three males (age $44 \pm 17$ years) with sinus rhythm and conduction disturbances underwent non-invasive ECGI in combination with CT or MRI using the Amycard 01C EP lab system (EP Solutions SA, Switzerland) before VT ablation. Two patients had right bundle branch block (RBBB), and one had left anterior branch block (LABB)). Multichannel ECG was recorded in 208-216 leads.

For all patients before operation, Carto LAT maps were created for each ventricle during sinus rhythm with the appropriate bundle brunch block. For this purpose, a Carto PENTARAY Catheter (Biosense Webster, Inc., US) was used. Mapping points were evenly distributed over the endocardial surface of the heart chamber. After the procedure, all LAT maps and electrograms were reviewed. The quality of ventricle models was improved by removing excess heart tissue, smoothing projections and adding vessels and valve ostia. Non-valid mapping points were deleted. References in every electrogram point and local activation times were corrected if necessary.

The examples of ECG in 12 leads during invasive mapping are represented in Figure 1. 

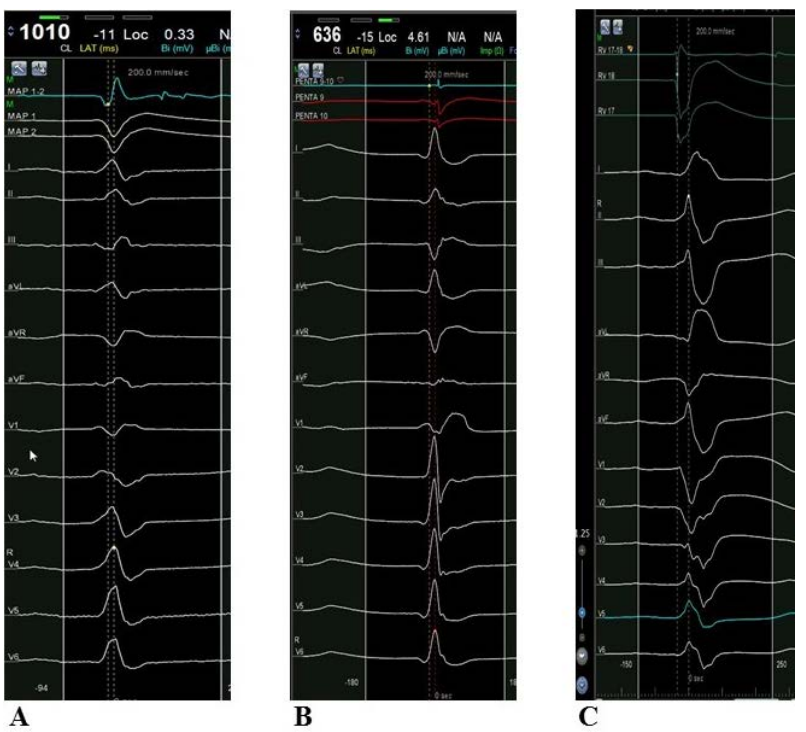

Figure 1. Examples of single complexes of 12-lead ECG recorded during CARTO LAT mapping. A. Case 1. Complex with RBBB. B. Case 2. Complex with RBBB. C. Case 3. Complex with LABB.

Finally, CARTO LAT maps included 120-397 electrograms (EGs) for the right ventricular (RV) endocardial surface and 530-962 EGs for the left ventricular (LV) endocardial surface (Table 1).

Table 1. Number of electrograms for the CARTO LAT map.

\begin{tabular}{lllc}
\hline$\#$ & \multicolumn{2}{c}{ \#EG on CARTO } \\
\cline { 2 - 4 } Case & $\begin{array}{l}\text { Interventricular } \\
\text { disturbance }\end{array}$ & LV & RV \\
\hline 1 & RBBB & 530 & 384 \\
2 & RBBB & 962 & 120 \\
3 & LABB & 766 & 397
\end{tabular}

Non-invasive activation maps were created using the Tikhonov regularization algorithm for electrical potentials in combination with the activation direction mapping (ADM) algorithm. Then the results of non-invasive and invasive mapping were evaluated, and activation maps for both methods were compared for each patient.

\section{Results}

For the first patient with RBBB, the early activation zones (EAZs) on the ADM map were localized in the RVOT anterior-septal wall, inferior-middle RV wall, and inferior-basal LV wall. Late activation zones (LAZs) were localized in the anterior-apical part of the LV. At the same time, the CARTO LAT map showed EAZ in the RV anterior-septal and LV septal walls and LAZ in the basal part of the inferior-lateral RV wall and LVOT (Figure 2).
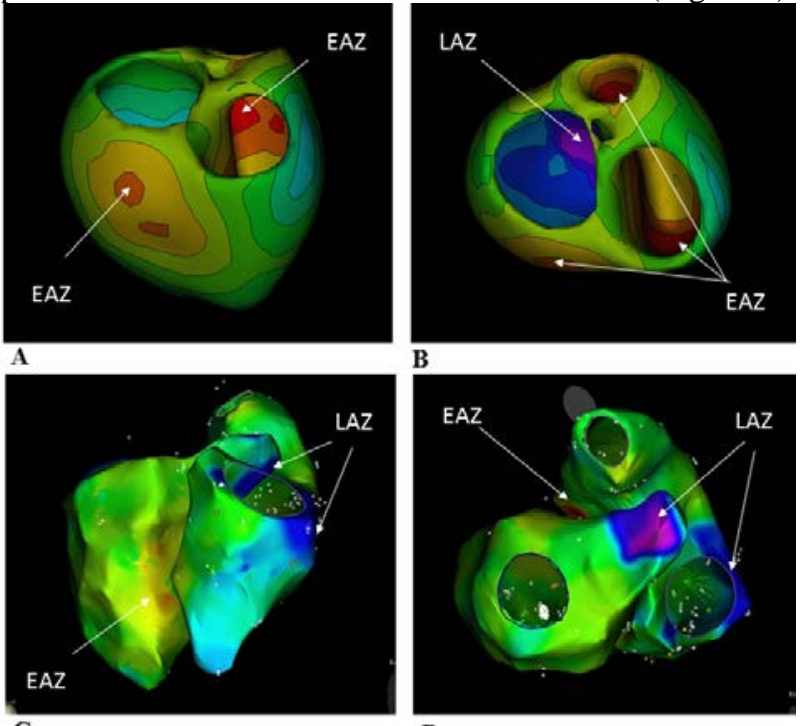

Figure 2. Case 1. A. ADM map. Postero-latera projection. B. ADM map. Superior projection. C. CARTO map. Postero-lateral projection. D. CARTO map. Superior projection.

For the second patient with RBBB, a non-invasive map showed the EAZ on the RV apex and LAZ in the LV apex. The CARTO LAT map showed the EAZ in the septal-apical LV wall, and LAZ was located in the RV lateral-basal wall (Figure 3).
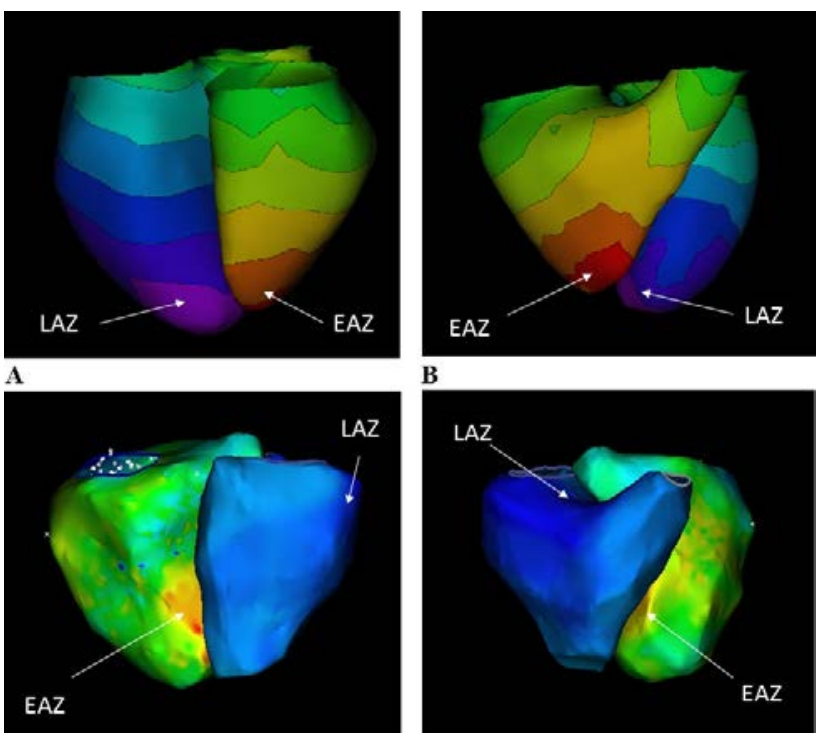

Figure 3. Case 2. A. ADM map. Posterior projection. B. ADM map. Anterior projection. C. CARTO map. Posterior projection. D. CARTO map. Anterior projection. 
For the third patient with LABB, the EAZ on the ADM map was localized on the RV apex, and LAZ was in the basal part of the antero-lateral LV wall. The CARTO LAT map showed the EAZ in the septal RV wall. The LAZs were located in the RVOT posterior wall, septalbasal RV wall and basal part of the infero-lateral LV wall (Figure 4). However, it is known that there was late contrast enhancement in the anterior-apical and middle part of the LV septum according to MRI data.
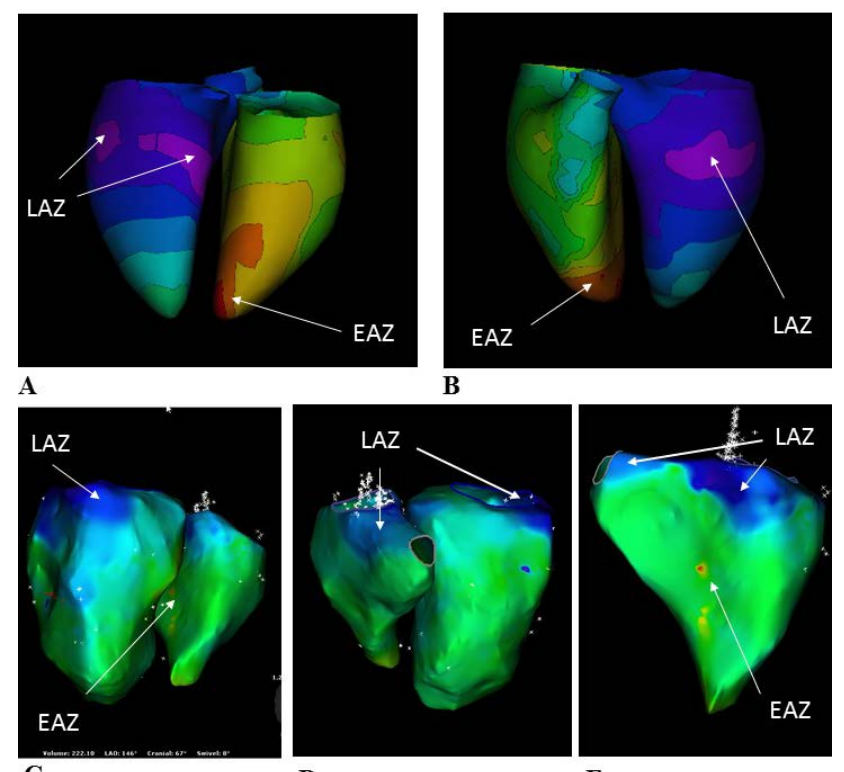

D

$\mathbf{E}$

Figure 4. Case 3. A. ADM map. Posterior projection. B. ADM map. Anterior projection. C. CARTO map. Posterior projection. D. CARTO map. Anterior projection. E. Carto map. Right ventricle. Septal projection.

The results of the early activation zone (EAZ) and late activation zone (LAZ) locations are presented in Tables 2 and 3.

Table 2. The results of EAZ location for patients with interventricular conduction disturbances.

\begin{tabular}{|c|c|c|c|}
\hline \multirow{2}{*}{$\begin{array}{l}\# \\
\text { Case }\end{array}$} & \multicolumn{3}{|c|}{ Early activation zone } \\
\hline & $\begin{array}{l}\text { Interventricular } \\
\text { disturbance }\end{array}$ & ECGI & CARTO \\
\hline 1 & RBBB & $\begin{array}{l}\text { RVOT anterior- } \\
\text { septal wall, } \\
\text { inferior-middle } \\
\text { RV wall, } \\
\text { inferior-basal } \\
\text { LV wall. }\end{array}$ & $\begin{array}{l}\text { RV anterior- } \\
\text { septal and LV } \\
\text { septal walls. }\end{array}$ \\
\hline 2 & RBBB & RV apex & $\begin{array}{l}\text { Septal-apical } \\
\text { LV wall }\end{array}$ \\
\hline 3 & LABB & RV apex & $\begin{array}{l}\text { Septal } \quad \text { RV } \\
\text { wall }\end{array}$ \\
\hline
\end{tabular}

Table 3. The results of LAZ location for patients with interventricular conduction disturbances.

\begin{tabular}{|c|c|c|c|}
\hline \multirow{2}{*}{$\begin{array}{l}\# \\
\text { Case }\end{array}$} & \multicolumn{3}{|c|}{ Late activation zone } \\
\hline & $\begin{array}{l}\text { Interventricular } \\
\text { disturbance }\end{array}$ & ECGI & CARTO \\
\hline 1 & $\mathrm{RBBB}$ & $\begin{array}{l}\text { Anterior- } \\
\text { apical part } \\
\text { of LV }\end{array}$ & $\begin{array}{l}\text { Basal part of } \\
\text { inferior-lateral } \\
\text { RV wall, } \\
\text { LVOT }\end{array}$ \\
\hline 2 & RBBB & LV apex & $\begin{array}{l}\text { Lateral-basal } \\
\text { RV wall }\end{array}$ \\
\hline 3 & LABB & $\begin{array}{l}\text { Basal part } \\
\text { of antero- } \\
\text { lateral LV } \\
\text { wall }\end{array}$ & $\begin{array}{l}\text { RVOT } \\
\text { posterior wall, } \\
\text { septal-basal } \\
\text { RV wall and } \\
\text { basal part of } \\
\text { infero-lateral } \\
\text { LV wall }\end{array}$ \\
\hline
\end{tabular}

\section{Discussion}

This study found differences in the activation patterns between invasive and non-invasive maps.

According to the invasive maps of the first and second patients with an RBBB-type ECG, myocardial activation began with the LV septum and with the anterior septal RV wall, respectively. Such results corresponded with the theoretical and experimental data but did not match completely [7, 8]. For instance, the results of work reproducing abnormal activation sequences caused by RBBB in 3D ventricular models showed that excitation propagation began in the left half of the Purkinje system. This pattern was very similar to the activation pattern under normal conditions, which started in the middle of the LV septum, on the high part of the anterior paraseptal and lower posterior paraseptal LV walls. The RV is excited via the left muscle mass with a delay. The latest activation was displayed in the postero-basal part of the $\mathrm{LV}$ and basal parts of the RV $[7,8]$.

It seems that most of the results of non-invasive maps were worse. Neither of the two activation maps showed the EAZ starting in the septum. This might be caused by the worse performance of algorithms of Tikhonov regularization for electrical potentials and the ADM algorithm in the septal region.

For the third patient, the activation patterns were also different from the literature data based on vector electrocardiographic descriptions. Some previous experimental studies in animals and humans showed delays in anterior-superior LV wall activation. In addition, a study of epicardial mapping of four men 
during coronary bypass surgery reported that all patients with LABB showed normal RV and inferior LV breakthrough sites and activation sequences. In the apical region of the anterolateral $\mathrm{LV}$ wall, breakthrough was observed in two patients. The basal part of the anterolateral LV wall was the latest site of LV activation [9]. Our patient had scars in the anterior-apical and middle parts of the LV, which could have led to the differences in the results.

\section{Conclusions}

Activation maps created using CARTO LAT and ADM maps allow us to display the excitation propagation in patients with intraventricular conduction disturbance during sinus rhythm. However, the activation patterns of invasive and non-invasive methods sometimes do not completely match the literature descriptions. This implies the need to improve activation map building algorithms.

Disclosure: M. Budanova, S. Zubarev - clinical application specialists of EP Solutions Company.

D. Potyagaylo, M. Chmelevsky - employees of EP Solutions Company.

\section{References}

[1] Revishvili AS, Wissner E, Lebedev DS, Lemes C, Deiss S, Metzner A, Kalinin VV, Sopov OV, Labartkava EZ, Kalinin AV, Chmelevsky M, Zubarev SV, Chaykovskaya MK, Tsiklauri MG, Kuck KH. Validation of the mapping accuracy of a novel non-invasive epicardial and endocardial electrophysiology system. Europace. 2015 Aug;17(8):1282-8.

[2] Wissner E, Revishvili A, Metzner A, Tsyganov A, Kalinin V, Lemes C, Saguner AM, Maurer T, Deiss SS, Sopov O, Labarkava E, Chmelevsky M, Kuck KH. Noninvasive epicardial and endocardial mapping of premature ventricular contractions. Europace. 2017 May 1;19(5):843-849.

[3] Tsyganov A, Wissner E, Metzner A, Mironovich S, Chaykovskaya M, Kalinin V, Chmelevsky M, Lemes C, Kuck KH. Mapping of ventricular arrhythmias using a novel noninvasive epicardial and endocardial electrophysiology system. J Electrocardiol. 2018 Jan - Feb;51(1):92-98.

[4] Chmelevsky M, Zubarev S, Budanova M, Treshkur T, Lebedev D. Validation of noninvasive epiendocardial electrocardiographic imaging accuracy using left ventricular epicardial pacing. Vestnic Aritmologii. 2019;95(1):5-16. (In Russ.)

[5] Chmelevsky M, Zubarev S, Budanova M, Treshkur T, Lebedev D. Validation of noninvasive epiendocardial electrocardiographic imaging accuracy using right ventricular endocardial pacing. Vestnic Aritmologii. 2019;96(2):19-28. (In Russ.)

[6] Ploux S, Lumens J, Whinnett Z, Montaudon M, Strom M, Ramanathan C, Derval N, Zemmoura A, Denis A, De Guillebon M, Shah A, Hocini M, Jaïs P, Ritter P, Haïssaguerre M, Wilkoff BL, Bordachar P. Noninvasive electrocardiographic mapping to improve patient selection for cardiac resynchronization therapy: beyond QRS duration and left bundle branch block morphology. J Am Coll Cardiol. 2013 Jun 18;61(24):2435-2443.

[7] Tusscher KH, Panfilov AV. Modelling of the ventricular conduction system. Prog Biophys Mol Biol. 2008 Jan-Apr;96(1-3):152-70

[8] Durrer, D., Van Dam, R.T., Freud, G.E., Janse, M.J., Meijler, F.L., Arzbaecher, R.C., 1970. Total excitation of the isolated human heart. Circulation 41, 899-912.

[9] Wyndham CR, Meeran MK, Smith T, Engelman RM, Levitsky S, Rosen KM. Epicardial activation in human left anterior fascicular block. Am J Cardiol. 1979 Oct;44(4):638-44.

Address for correspondence

Name: Margarita Budanova

Full postal address: 2 Akkuratova, Almazov National Medical Research Center, Saint-Petersburg, 1973411, Russia.

E-mail address: budanovamargarita@gmail.com 